\title{
Avaliação de seis testes sorológicos no diagnóstico da brucelose bubalina ${ }^{1}$
}

\author{
László Molnár ${ }^{2}$, Éva Molnár ${ }^{2}$, Emilia S.C. Lima² e Hilma L.T. Dias ${ }^{2}$
}

\begin{abstract}
Molnár L., Molnár E., Lima E.S.C. \& Dias H.L.T. 2002. [Evaluation of six serological tests for the diagnosis of brucellosis in water buffaloes.] Avaliação de seis testes sorológicos no diagnóstico da brucelose bubalina. Pesquisa Veterinária Brasileira 22(2):41-44. Centro Agropecuário, Lidea, Universidade Federal do Pará, Belém, PA 66075-900, Brazil.

Four hundred and forty buffalo sera, selected from about 1,200 blood samples of another study, were examined. The samples were tested by six serological methods: two of agglutination, two of indirect ELISA and two of competitive ELISA. To determine the relative sensitivity and specificity of different tests, animals with a positive result to competitive ELISA of the FAO/IAEA were considered as infected. The relative sensitivity of competitive ELISA, indirect ELISA with conjugate anti-bovine light chain monoclonal antibody labelled with HRPO, indirect ELISA with anti-bovine IgG conjugate, rose Bengal test and rapid slide agglutination test was $100 \%, 98.57 \%, 97.14 \%, 91.42 \%$ and $79.28 \%$, and the relative specificity $99.33 \%, 97.33 \%$, $95.66 \%, 94.00 \%$ and $86.33 \%$, respectively. The value of the different serological tests for the diagnosis of brucellosis is discussed.
\end{abstract}

INDEX TERMS: Brucellosis, water buffalo, competitive ELISA, indirect ELISA, agglutination.

RESUMO.- Foram examinados 440 soros bubalinos, selecionados em um outro exame de cerca de 1200 amostras sangüíneas. Utilizaram-se seis diferentes testes sorológicos para o exame dessas amostras: dois de aglutinação, dois de ELISA indireto e dois de ELISA competitivo. Os animais positivos no ELISA competitivo da FAO/IAEA foram considerados como infectados, e a comparação com os resultados dos outros testes aconteceu neste sentido. A sensibilidade relativa foi de $100 \%, 98,57 \%, 97,14 \%, 91,42 \%$ e $79,28 \%$, e a especificidade relativa de $99,33 \%, 97,33 \%, 95,66 \%, 94,00 \%$ e $86,33 \%$ nas provas de ELISA competitivo, ELISA indireto com conjugado antibovino de cadeia leve (anticorpo monoclonal com HRPO), ELISA indireto com conjugado contra IgG bovino total, teste do antígeno acidificado tamponado e aglutinação rápida, respectivamente. Discute-se o valor dos diferentes testes sorológicos no diagnóstico da brucelose.

TERMOS DE INDEXAÇÃO: Bucelose, bubalino, ELISA competitivo, ELISA indireto, aglutinação.

\footnotetext{
${ }^{1}$ Aceito para publicação em 22 de agosto de 2001.

Este trabalho contou com o apoio da Joint FAO/IAEA, Agriculture and Biotechnology Laboratory, Agency Laboratories Dividion, Seibersdorf, Austria, e do Dr. K.H Nielsen, ADRI, Nepean, Ontario, Canada.

${ }^{2}$ Laboratório de Investigação e Diagnóstico de Enfermidades Animal (LIDEA), Centro Agropecuário, Universidade Federal do Pará.
}

\section{INTRODUÇÃO}

$O$ controle eficiente e sobretudo a erradicação da brucelose é baseado no diagnóstico seguro. Para o diagnóstico populacional dessa doença são adequadas somente as provas sorológicas. Entre as provas sorológicas, a aglutinação em tubo (Serum Agglutination Test, SAT) foi utilizada mais amplamente até cerca de 1967, sendo aproveitada nos primeiros esquemas de erradicação da doença nos países europeus (Sutherland 1980). Entretanto, várias vezes, foi isolada Brucella abortus em vacas com título baixo de aglutininas ou sem soroconversão nessa prova (Renoux et al. 1968, Nicoletti 1969). Por isso, foram realizadas comparações entre as diversas provas disponíveis naquela ocasião, examinando amostras provenientes de animais infectados, comprovado pelo isolamento de B. abortus, e amostras colhidas em rebanhos sabidamente livres da infecção. Esses exames demonstraram que o teste de fixação de complemento (FC) é superior à SAT, sendo a prova mais fidedigna (Nicoletti 1969, Morgan \& Richards 1974, Alton et al. 1975) e tornando-se, na maioria dos países, na prova confirmatória.

Com o decorrer do tempo, acumularam-se dados sobre os vários defeitos apresentados pela prova de FC, como por exemplo a ação anticomplementar, o fenômeno de prozona e a sensibilidade insuficiente (Sutherland 1980).

Os ELISA são os mais multifacetados entre os méto- 
dos diagnósticos, e detectam quase qualquer molécula imunorreativa. Diferentes formas de ELISA são utilizadas para diversos fins, e nos últimos 20 anos têm sido empregadas para o diagnóstico de muitas enfermidades infecciosas, entre elas as bruceloses de diversas espécies animais e a do homem (Mathias \& MacMillan 1995, Nielsen et al. 1995, Corbel \& MacMillan 1996, Mathias et al. 1998, Baldi et al. 1999, Lucero et al. 1999, Samartino et al. 1999).

No Brasil, atribui-se importância elevada à soroaglutinação. Segundo Feitosa et al. (1991), a SAT e a SAR (soroaglutinação rápida) são provas usadas para o diagnóstico individual da brucelose. Corrêa \& Corrêa (1992) também ressaltam o papel quase exclusivo da soroaglutinação. Por outro lado, Corbel \& MacMillan (1996) declararam que a SAT é inferior a outros testes em especificidade e sensibilidade e não é recomendada se outros testes estiverem disponíveis. A propósito de comércio internacional, vários países, entre eles os da União Européia, ressaltam que a SAT é inadequada (a SAR não é mencionada entre as possibilidades), e, se não disponível outra prova, o título aglutinante na SAT não pode ultrapassar $30 \mathrm{UI}$ (que corresponde a uma diluição cerca de 1:12). A OIE (Office International des Epizooties), atualmente, aceita os resultados do teste do antígeno acidificado tamponado e releva o uso da FC e dos ELISA, ressaltando a superioridade do ELISA competitivo (Corbel \& MacMillan 1996).

O objetivo deste trabalho foi o de comparar os resultados obtidos de seis testes sorológicos, examinando amostras colhidas de bubalinos e selecionadas durante um levantamento sorológico.

\section{MATERIAL E MÉTODOS}

\section{Soros examinados}

Em um inquérito sorológico, realizado no mesmo laboratório, foram examinadas cerca 1200 amostras de soro bubalino pelo ELISA da FAO/IAEA (Competitive Brucellosis ELISA). Dessas amostras, foram selecionados 440 soros e examinados em seis diferentes provas (duas de aglutinação, duas de ELISA indireto e duas de ELISA competitivo). A escolha dos 440 soros foi realizada do seguinte modo: somente soros de excelente qualidade (sem o menor traço de hemólise); soros de vacas com idade superior a três anos; soros de rebanhos livres, com prevalência baixa, média e alta da infecção; e soros com valores PP baixos, perto do ponto de corte (suspeitos) e altos.

\section{Testes sorológicos}

Soroaglutinação rápida (SAR). A prova foi realizada em placa, de acordo com as recomendações do fabricante (Tecpar, Instituto de Tecnologia do Paraná), utilizando-se quatro diferentes quantidades de soro. $\mathrm{O}$ antígeno foi produzido $\operatorname{com} B$. abortus cepa 1119-3.

Teste do antígeno acidificado tamponado (AAT). Foi realizado conforme descrito pelo Instituo de Tecnologia do Paraná. Qualquer reação visível foi considerada como positiva.

ELISA indireto (iELISA). Utilizou-se o kit ELISA, preparado pela Animal Production Unit, FAO/IAEA, Agriculture and Biotechnology Laboratory, Agency's Laboratories Division, Seibersdorf, Austria: Indirect enzyme-linked immunosorbent assay (ELISA) for bovine brucellosis. 0 teste foi executado conforme as recomendações da agência, com as seguintes modificações: a) iELISA-1: utilizou-se conjugado antibovino de cadeia leve (anticorpo monoclonal com HRPO), fornecido pelo K. H. Nielsen do Nepean, Ontário, Canadá; e b) iELISA-2: no qual foi utilizado conjugado contra $\operatorname{Ig} G$ total bovino (Sigma).

ELISA competitivo 1 (cELISA-1). O kit ELISA foi fornecido pela FAO/IAEA, e o processamento, basicamente, está de acordo com a descrição de Nielsen et al. (1995). O antígeno foi constituído de lipopolissacáride liso (sLPS) de B. abortus cepa 1119-3, extraído pelo método água/fenol quente. $O$ anticorpo monoclonal (M84), específico para um epítopo do o-polissacáride de sLPS, foi produzido no Canada (ADRI, Nepean, Ontário). O conjugado foi um anticorpo goat antimouse $\operatorname{IgG}(\mathrm{H}+\mathrm{L})$ (Jackson). $\mathrm{O}$ substrato foi o peróxido de hidrogênio, e como cromógeno utilizou-se ABTS (Sigma).

ELISA competitivo 2 (cELISA-2). Foi utilizado um kit ELISA comercial (Svanova, Brucella abortus C-ELISA), e o teste foi realizado conforme recomendação do fornecedor.

Os soros foram examinados em diluição de 1:200 nos ELISA indireto e 1:20 nos ELISA competitivo, de acordo com a recomendação dos fornecedores.

Os resultados do cELISA-1 foram aceitos como referência, e a comparação com os resultados dos outros testes aconteceu neste sentido.

\section{Análise estatística}

A análise estatística foi efetuada de acordo com os parâmetros utilizados por Nielsen et al. (1992). Para a determinação da sensibilidade e especificidade relativas dos testes foram empregadas as seguintes fórmulas:

$$
\text { Especificidade }=\frac{\text { positivos no teste }}{\text { positivos no cELISA-1 }} \times 100
$$

$$
\text { Sensibilidade }=\frac{\text { negativo real ao teste }}{\text { total de negativos testados }} \times 100
$$

\section{RESULTADOS}

Os resultados obtidos por meio das diferentes provas estão indicados no Quadro 1. Os números positivos e negativos totais estão próximos um do outro (140-142 e 298-300, respectivamente), exceto na SAR. Já em número positivo e negativo real, a diferença foi maior (128-140 e 282-300, respecti-

Quadro 1. Resultados numéricos obtidos em seis testes sorológicos para o diagnóstico da brucelose, pela análise de 440 soros bubalinos

\begin{tabular}{lccccccc}
\hline \multirow{2}{*}{ Teste } & \multicolumn{3}{c}{ Positivo } & & \multicolumn{3}{c}{ Negativo } \\
\cline { 2 - 3 } & Total & Real $^{1}$ & Falso & & Total & Real $^{2}$ & Falso \\
\hline cELISA-1 & 140 & 140 & & & 300 & 300 & \\
cELISA-2 & 141 & 140 & 1 & & 299 & 298 & 1 \\
iELISA-1 & 142 & 138 & 4 & & 298 & 292 & 6 \\
iELISA-2 & 141 & 136 & 5 & & 299 & 287 & 12 \\
RB & 141 & 128 & 13 & & 299 & 282 & 17 \\
SAR & 126 & 111 & 15 & & 314 & 259 & 55
\end{tabular}

${ }^{1}$ Número de amostras que foram positivas também no cELISA-1.

2 Número de amostras que foram negativas também no cELISA-1. 
Quadro 2. Dados estatísticos relativos dos seis testes para o diagnóstico sorológico da brucelose em búfalos, calculados a partir dos resultados do cELISA-1

\begin{tabular}{lcccccc}
\hline Teste & Concordância & $\begin{array}{c}\text { Sensibilidade } \\
\text { diagnóstica }\end{array}$ & $\begin{array}{c}\text { Confiança } \\
\text { limite }(95 \%)\end{array}$ & $\begin{array}{c}\text { Especificidade } \\
\text { diagnóstica }\end{array}$ & $\begin{array}{c}\text { Confiança } \\
\text { limite (95\%) }\end{array}$ & $\begin{array}{c}\text { Kappa } \\
\text { valor }\end{array}$ \\
\hline cELISA-2 & 99,54 & 100,00 & 0,0294 & 99,33 & 0,0624 & 0,9894 \\
iELISA-1 & 97,72 & 98,57 & 0,0295 & 97,33 & 0,0613 & 0,9480 \\
iELISA-2 & 96,13 & 97,14 & 0,0294 & 95,66 & 0,0603 & 0,9123 \\
AAT & 93,18 & 91,42 & 0,0294 & 94,00 & 0,0593 & 0,8446 \\
SAR & 79,54 & 79,28 & 0,0259 & 86,33 & 0,0615 & 0,5429
\end{tabular}

vamente). Os resultados obtidos na SAR diferem bastante em relação aos outros testes, e especialmente quanto ao número de amostras falso-negativas, que foi muito alto (55). Os dados estatísticos encontram-se no Quadro 2.

\section{DISCUSSÃO}

Para o diagnóstico populacional da brucelose somente os testes sorológicos são convenientes. $\mathrm{O}$ diagnóstico sorológico constitui uma das principais bases em que se apóiam os programas de controle da brucelose. Sem o diagnóstico correto torna-se praticamente impossível realizar programas de erradicação. Assim, a disponibilidade de métodos confiáveis para o diagnóstico é essencial em campanhas de combate às doenças infecciosas, dentre elas a brucelose.

O número de provas sorológicas disponíveis é grande, tornando-se imperioso a escolha das mais adequadas para $o$ objetivo determinado. No caso da brucelose humana e bovina, a técnica de ELISA conquistou espaço nos últimos quinze anos (Mathias \& MacMillan 1995, Nielsen et al. 1995, Corbel \& MacMillan 1996, Molnár et al. 1998, Baldi et al. 1999, Lucero et al. 1999, Samartino et al. 1999). A respeito do diagnóstico da brucelose em búfalos foram publicados poucos estudos com a utilização da técnica de ELISA (Guedes et al. 1997, Mathias et al. 1998, Lopes et al. 1999).

No presente trabalho foram utilizados seis testes com o intuito de avaliar suas respectivas sensibilidades e especificidades, tendo como referência o resultado obtido no cELISA 1. Sabe-se que, sem exames bacteriológicos minuciosos, torna-se difícil discutir esses parâmetros. Por essa razão, a escolha do cELISA-1 como teste de referência foi arbitrária. No entanto, acredita-se que essa escolha foi correta. Mathias et al. (1998) constataram que um ELISA competitivo foi excelente como teste para examinar soros bubalinos. Esse mesmo teste (cELISA-1) identificou todos os 636 bovinos dos quais foram isolados B. abortus (sensibilidade de $100 \%$ ) e apresentou especificidade de 99,7\% quando foram examinandos 1446 soros de bovinos oriundos de rebanhos livres da infecção (Nielsen et al. 1995). No laboratório, em que o presente trabalho foi realizado, encontrou-se uma vaca bubalina idosa da qual se isolou $B$. abortus de uma bursa com pus, sendo o soro dessa vaca negativo nas provas de soroaglutinação rápida, lenta e na fixação do complemento, e positivo no cELISA1 (Guedes et al. 1997).

Já nos anos 60 e 70 foi comprovado que as provas de aglutinação poderiam conferir resultados falso-negativos em casos de infeções antigas, ou seja, em animais que se infectaram com Brucella vários anos antes da realização da prova (Nicoletti 1969; Morgan \& Richards 1974, Alton et al. 1975, Sutherland 1980). Por essa razão, na última fase de um programa de erradicação da brucelose, as vacas com mais de 10 anos de idade, apesar de soronegativas, foram eliminadas do rebanho (Szent-Iványi \& Mészáros 1985).

O número total de amostras positivas e negativas foi muito semelhante nos ELISAs e no AAT (Quadro 1). Entretanto, no AAT 13 amostras foram falso-positivas e 17 falso-negativas. Convém notar que os valores PP das amostras falso-positivas e falso-negativas em todos os ELISAs sempre estiveram próximos do valor de corte (resultados incertos ou suspeitos). Desta forma, seria ideal reexaminar os animais suspeitos. $\mathrm{O}$ número de amostras falso-negativas no AAT foi bastante alto (17), e isso é surpreendente, já que esse teste é aceito como adequado para triagem da brucelose (Corbel \& MacMillan 1996). Os resultados obtidos na SAR demonstram que essa prova é inapta para proporcionar resultados confiáveis.

Desta forma, o ELISA competitivo pode representar um recurso útil para o diagnóstico da brucelose bubalina. Estes resultados estão de acordo com obtidos por Mathias et al. (1998). O ELISA indireto, utilizando-se o conjugado antibovino preparado com anticorpo monoclonal para cadeia leve, também apresentou boa sensibilidade e especificidade, corroborando as recomendações oficiais da OIE (Corbel \& MacMillan 1996).

\section{REFERÊNCIAS}

Alton G.G., Maw J., Rogerson B.A. \& Mc Pherson G.G. 1975. The serological diagnosis of bovine brucellosis: an evaluation of the complement fixation, serum agglutination and rose Bengal tests. Aust. Vet. J. 51:57-63.

Baldi P.C., Araj G.F., Racaro G.C., Wallach J.C. \& Fossati C.A. 1999. Detection of antibodies to Brucella cytoplasmatic proteins in the cerebrospinal fluid of patients with neurobrucellosis. Clin. Diag. Lab. Immunol. 6:756-759.

Corbel M.J. \& MacMillan A.P. 1996. Bovine brucellosis, p. 242-255. In: Manual of Standards for Diagnostic Tests and Vaccines. OIE, Paris, France.

Corrêa W.M. \& Corrêa C.N.M. 1992. Enfermidades Infecciosas dos Mamíferos Domésticos. $2^{\mathrm{a}}$ Edição, MEDSI, Rio de Janeiro, p.202.

Feitosa M.H., Bittar C.R. \& Gomes S.P. 1991. Brucelose: levantamento sorológico no Estado de São Paulo no período de 1977 a 1987. Vet. Zootec., Botucatu, 3:9-15.

Guedes V.T.M., Molnár L., Molnár E. \& Silva A.O.A. 1997. Exames sorológicos e bacteriológicos a respeito da brucelose bubalina no Estado do Pará. Anais XXV Congr. Bras. Med. Veterinária, 20-24 out., Gramado, RS, p. 158.

Lopes C.F.A., Molnár L. \& Molnár E. 1999. Avaliação soroepidemiológica da brucelose em animais e humanos procedentes da zona Bragantina no Estado do Pará-Brasil. Revta Bras. Reprod. Anim. 23:429-431.

Lucero N.E., Foglia L., Ayala S.M., Gall D. \& Nielsen K. 1999. Competitive 
enzyme immunoassay for diagnosis of human brucellosis. J. Clin. Microbiol. 37:3245-3248.

Mathias L.A. \& MacMillan A.P. 1995. Comparação de conjugados no teste imunoenzimático competitivo para o diagnóstico da brucelose bovina. Pesq. Vet. Bras. 14:19-23.

Mathias L.A., Chaves L.F., Gírio R.J.S. \& Del Fava C. 1998. Avaliação de um teste imunoenzimático competitivo no diagnóstico sorológico da brucelose em búfalos (Bubalus bubalis). Pesq. Vet. Bras. 18:111-114.

Molnár E., Molnár L. \& Wale W.G. 1998. Value of different serological tests in the diagnosis of bovine brucellosis in the Amazonian region. Acta Vet. Hung. 46:199-210.

Morgan W.J.B. \& Richards R.A. 1974. The diagnosis, control and eradication of bovine brucellosis in Great Britain. Vet. Rec. 94:510-517.

Nicoletti P. 1969. Further evaluations of serologic test procedures used to diagnose brucellosis. Am. J. Vet. Res. 30:1811-1816.
Nielsen K.H., Gall D., Kelly W., Henning D. \& Garcia M.M. 1992. Enzymeimmunoassay: application to diagnosis of bovine brucellosis. Monograph, Agriculture Canada, Nepean, Ontario, p. 1-203.

Nielsen K.H., Kelly L., Gall D., Nicoletti P. \& Kelly W. 1995. Improved competitive enzyme immunoassay for the diagnosis of bovine brucellosis. Vet. Immunol. Immunopath. 46:385-291.

Renoux G., Philippon A. \& Plommet M. 1968. Valeur des faibles titres agglutinants pour le diagnostic de la brucellose bovine. Bull. Acad. Vét. Fr 41:378-381.

Samartino L., Gall. D., Gregoret R. \& Nielsen K. 1999. Validation of enzymelinked immunosorbent assays for the diagnosis of bovine brucellosis. Vet. Microbiol. 70:193-200.

Sutherland S.S. 1980. Immunology of bovine brucellosis. Vet. Bull. 50:359-368.

Szent-Iványi T. \& Mészáros J. 1985. Doenças Infecciosas dos Animais Domésticos (In Hungarian). Mezögazdasági Kiadó, Budapest, p.194-207. 